\title{
S2)

\section{Transdisciplinarity at the Boundaries: Exploring a Sylvan Metaphor for Health} Peter J. Whitehouse, MD-Ph.D. Professor, Case Western Reserve University and University of Toronto; President,
Intergenerational Schools International. Email:peter.whitehouse@case.edu

Received 15 August, 2018; Revised 25 November, Accepted 20 January

Copyright (C)2018 Peter J. Whitehouse. This is an open access article distributed under the Creative Commons Attribution License (https://creativecommons.org/licenses/by/4.0/), which permits unrestricted use, distribution, and reproduction in any medium, provided the original work is properly cited.

Available online 25 January, 2019 at www.atlas-journal.org, doi: 10.22545/2019/0114

\section{T} ransdisciplinarity is an action oriented intellectual and ethical endeavor to address complex ecological, economic, and political challenges that humans face. Language is viewed as a powerful tool for necessary cultural change. Blending art and science looking for the difficult to define but critically important hidden spaces between apparently rigid conceptual structures is a core of transdisciplinarity. Metaphor is a particular powerful tool for examining boundaries and developing creative blends of structures and processes. Forests are biologically and culturally critical to life on the planet. In this paper we explore, a performance character named Sylvanus, the Tree Doctor, named after the Roman god of forests and boundaries. We consider the importance of intergenerational learning as a process for deeper reflection on human responsibility over time. Transdisciplinarity is energized by intergenerativity and collective wisdom. Systemic and holistic conceptions of health will be essential for the survival and reinvention of human civilization in better balance with planetary ecosystems.
Keywords: Transdisciplinarity, hidden third, intergenerativity, human sciences, climate change, performance art, tree doctoring, intergenerational learning

\section{Introduction}

The core of transdisciplinarity is a moral and intellectual commitment to the processes of exploring boundaries among academic silos in service of addressing complex human and eco-system challenges [1]. Intergenerativity is the blending of different sources of creativity in order to create novel innovations to address social challenges. Intergenerativity is the energy to go between (inter) in order to go beyond (trans) [2]. Transdisciplinarity recognizes different levels of reality and encourages addressing complexity. This approach also celebrates the socalled hidden third, which can be manifest as the logic of the included middle and other places of generative uncertainty. The logical boundaries between A and not-A may appear to be clear and fixed and to 
exclude any middle zone, but transdisciplinarity explores the dynamism of transitions and their possible fuzzy set relationships. Like the fluid boundaries between the Oriental Yin and Yang, black can include white and white can include black. Sexual and gender categories can be much more diverse than purely male and female. By embracing complexity, mystery and awe into our discourse space transdisciplinarity encourages thinking and valuing that transcends pure scientific rationality and admits into discussion the poetic, mystical, and spiritual.

Transdisciplinary attends to the power of language and story embraced by the humanities, as well as the methods of the sciences. Figures of speech, particularly metaphor, are key because such linguistic devices carry one world of meaning into another. They asked us to compare and contrast different intellectual and value domains looking for parallels and divergences. Other forms of metaphor are also studied and employed including auditory and visual. Thus transdisciplinarity encourages the arts to contribute to revealing and understanding complexity. In our techno-scientific world we think of culture change occurring as a result of the rational pursuit of more advanced knowledge. Progress is seen as material. Rather art helps us understand the often-ineffable aspects of our humanity and opens up channels for culture change that the sciences do not. Moreover the humanities and the attendant critical thinking and deeper ethical considerations offer us opportunities to challenge dominant narratives about what it means to be a human being and to make cultural progress $[3,4]$.

The boundaries between art and science represent a particularly important area of exploration for transdisciplinarity. The powers of imagination manifest more through story and image than through scientific method. After all, we write fiction, fantasy, and invented the novel. Transdisciplinarity seeks to understand what art and science contribute that are similar and what are different as expressions of our minds and spirits. Both art and science explore relationships and processes existent in the world, as well as in the human mind. They both attend to the recognition and creation of patterns. The ability to recognize patterns in the world and to manipulate them is a fundamental human capability. Our instinct to find patterns in the world in fact leads us to create some individual mental patterns that may not be evident to all others in the real world or may not exist at all. Cultures share patterns of thinking based on common values. The conversation between subjectivity and objectivity is rich in art, often neglected in science. The exaggerated claims that science is the only true source of knowledge about the world leads to the unwarranted faith that characterizes scientism. Transdisciplinary itself challenges our long-standing separation of the world into dualistic notions of objectivity and subjectivity. The understanding of one of the great mysteries of the universe (at least to our species), consciousness, needs more than the findings of human neurosciences but rather a richer embrace of emergent properties beyond our own individual brains.

Narrative is perhaps the fundamental way in which humans attempt to understand complexity. As mentioned, figures of speech allow us to find or imagine relationships among different sources of generativity and patterns of connections. The failure of science to fully embrace the power of narrative in its methodology is a limitation, particularly when it attempts to translate its inventions and discoveries into a space of innovation that might impact human life. The biomedical sciences are particularly prone to deny the power of narrative. When anecdotes (hidden stories) are disparaged as forms of knowledge to ignore, we run the risk of so-called epistemological bullying from other forms of knowledge creation. All forms of evidence have both strengths and weaknesses. Randomized controlled studies, for example, can fail in both replication and generalizability, yet they are touted by some as the only true form of health knowledge generation. Wisdom requires balancing diverse forms of evidence relevant to decision making including the use of mixed methods, i.e. combining quantitative and qualitative research methods.

In this article we will summarize and extend a paper presented at the CIRET/Atlas international transdisciplinary conference held in Transylvania in June 2018 at the Babes-Bolyai University. The author both chaired the session on becoming transdisciplinary in the human sciences and presented a paper entitled "Wising up: designing an intergenerational course for the future." The paper blends autobiography through performance art as one way to address the challenges of global climate change and other social unrest.

Our main character in this paper is the author as Sylvanus, the Tree Doctor [5]. This performance character is an artistic and perhaps also scientific 
device to help human audiences understand what we can learn about health broadly writ from trees and forests. To be clear this is not the usual use of the term tree doctor as a human who is responsible for the health of trees (an arborist as in a tree surgeon who removes dead branches, for example).

\section{The Transdisciplinary Nature of Tree Doctoring}

\subsection{History}

As a physician, cognitive neuroscientist, psycholinguist, and environmental bioethicist, I have long been curious about the boundaries between art and science and other complex conceptual interfaces like disciplines and professions. My own scientific activities have been inter-and then transdisciplinary from my undergraduate days as a premedical student and psychology major. I have worked in geriatric interprofessional team practices. My artistic interests have been based around photography and music. As my life and career moved through different phases as basic scientist to clinical researcher to public health and intergenerational learning practitioner and advocate, I came to see the arts as more and more important in improving health and changing culture $[2,5]$. I saw intergenerative collaborations between art and science as critical.

Hence my quests for understanding of and photographing in nature allowed my performance character as Tree Doctor to emerge starting in 2013 during one of many trips the Muir Woods (a redwood forest and national park in California). However, the Tree Doctor has had rebirths and emergences in the Amazon rainforest and in allegedly haunted forests of Transylvania. The fundamental purpose of performing as a Tree Doctor is to ask the audience what human beings can learn from trees and forests, especially about health. Trees are long-lived, inspiring creatures that are subject to biological diseases as well as human interventions. They teach about life, aging, and death. There are few things more alive than a decaying log.

\subsection{Name}

The Tree Doctor received his/her/its name during a study by the author of human cosmologies and geographies. Sylvanus is the Roman god often identi- fied with forests. In English "sylvan" or alternatively silvan means, relating to the forest so that Pennsylvania is the forest of William Penn and Transylvania means beyond the forest. However, in mythology Sylvanus is not actually just the god of forests but rather of boundaries between forests and other ecosystems, like fields and cities.

\subsection{Costume}

The Tree Doctor appears in costume. I dress in greens and browns, even including personally dyed green shoes. My signature T-shirt is an oak tree with a Yang and Yang symbol embedded in its branches. My usual hat is decorated with the quote of John Muir who said that the best way to understand the universe is to take a walk in a forest wilderness. Occasionally I use props such as a forest green stethoscope, a dryad (tree spirit wood nymph) doll, a replica of a matsutake mushroom, or owl puppets of different ages permitting interspecies and intergenerational conversations as part of the performance.

\subsection{Locations}

The Tree Doctor has performed in art museums, national medical and fundraising meetings, and clinical grand rounds in academic hospitals. At the University of Toronto an intergenerational dance collaborator and a graduate student colleague who studies theater accompanied me. In Cleveland on one occasion I was joined by friends and colleagues who are theater and community arts experts. Sylvanus has also participated in activities through Intergenerational Schools International to support learning about nature and health with children, youth, adults and elders. Intergenerational Schools [12] are based on relationship and narrative learning combined with rich educational experiences in social and natural communities. The three schools in Cleveland have been demonstrated to be valuable to both children and their learning and elders and their sense of purpose and quality of life. Now intergenerational learning programs are emerging in Europe and Asia as well.

\subsection{Bioscience}

Trees offer the potential for teaching us about biology $[6,7]$. They can be considered metaphorically as part of the respiration of the planet because they 
complement animals that breathe in oxygen and out carbon dioxide by doing the opposite. The trees play many complex roles in ecosystems, for example in water and nitrogen cycles. They sequester carbon and are one of the sources of fossil fuels including coal and oil. Trees live a long time, up to thousands of years, and their health records recorded in growth rings can help us understand long-term climate perspectives. The forests are homes for many other species. The consequences of commercial deforestation in terms of species extinction and climate change are well known. Human behavior has also altered the pattern of forest fires with devastating effects Yet wood and paper are still essential materials for human communities.

Trees also relate to our understanding of the information processing sciences. Trees sense changes in the environment, respond to those changes, and communicate with other species. For example, chemical messengers are often released in response to insect threats to a forest. Trees have an often-ignored hidden life under the ground where they interact both competitively and cooperatively with members of the same species, as well as others, for example fungi [7].

Besides their biological importance and role as teachers about ecosystems, trees are also a rich source of metaphor [8]. Throughout history, treelike structures have been employed to organize conceptstrees of knowledge. Darwin and many others used trees to describe the relationships between living creatures -trees of life. Individual trees tell us about the importance of branching out and seeking illumination through their phototropism (leaves growing towards light). Roots are geotropic (roots grow towards gravity) and can be used metaphorically to promote understanding our connections with the earth and the origins of those connections. Perhaps most critically for our purposes, the relationships between trees and forests demonstrate to human beings the importance of systems thinking i.e. neglecting to "see the forest for the trees" (or for that matter the trees for the forest).

An illustration of this big picture thinking comes from neuroscience where the Nobel Prize winner Ramon Cajal it is said to have developed his pioneering neuronal theory of the organization of the brain based on watching trees and forests pass by as he travelled on a train. He came to realize that the brain (the forest) which appeared whole in the sum- mertime was actually composed of individual trees (neurons) that are more visible as isolated structures in the winter. Neurons also look a bit like trees with branches and roots when stained with silver stains that the Cajal used to map the pattern of neurons in the brain. We still talk of arborization when describing neuronal connections.

\subsection{Cultural Shadows and Thinking Forest}

The cultural evolution of our species evolved from forest based hunter-gatherers, to settled farmers, and now most humans are urban dwelling workers of various kinds. Throughout this cultural change forests played an important part in the conversation about what it meant to be a human in relationship to our place in nature [9]. The earliest surviving mythologies, such as Epic of Gilgamesh in Mesopotamia, as well as later ones in Asia and elsewhere, speak of the power of forests, often manifest in divinities. Trees are very common subject for artistic portrayal and interpretation (see Figure 1).

Forests offer profound spiritual experiences manifest in various religious traditions and other practices. Today tree worshipers and other forms of shamanic communication with nature exist in tribes less influenced by Western civilization. Kohn [10] has called in fact for creating an anthropology beyond humans based on the idea that forests think. He suggests thought emerges through visual forms. Although forests clearly process information, it is a matter of definition as to whether they think or not. But what is clear is that forests are included in the thoughts of human beings as they seek to understand the biological and social significant of trees [10].

As human beings cleared forests and continued to do so in order to support agriculture, huge population growth occurred. Major changes occurred in human culture including the development of social hierarchies and complex economies. In this process forests were viewed as powerful sources of mystery, as well as resources. Wood was essential to the built environment of towns and cities and eventually to extensive shipbuilding with consequent interaction among different human groups.

The boundaries between ecosystems, so-called ecotomes, such as those between forests and fields or fields and cities, are places of active biological activity, including the exchange of genetic material and epigenetic factors which affect speciation. Similarly the boundaries between different cultures represent 


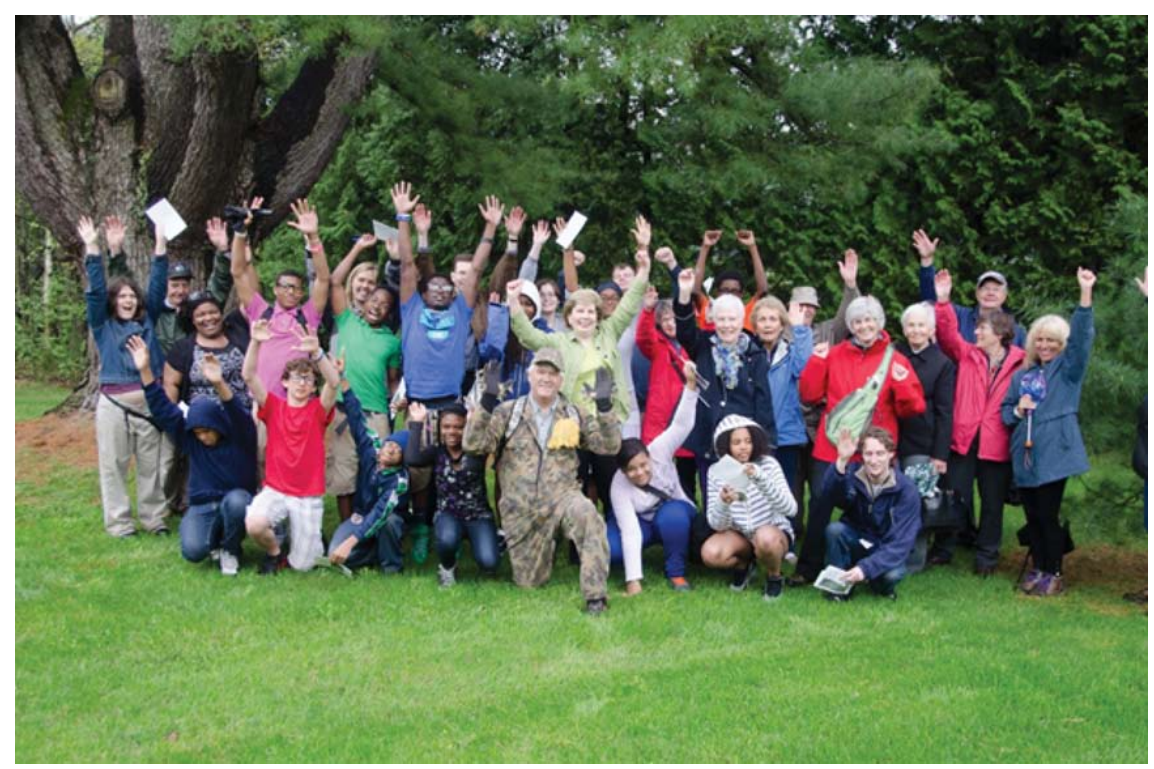

Figure 1: Students for the Intergenerational School in Cleveland celebrate learning with elders from Toronto in an arboretum. The Tree Doctor is kneeling center front dressed in camouflage with the wood nymph in his pocket. (photo courtesy of the Legacy Center).

intergenerative zones of cultural evolution. Immigration between national borders creates great tensions that can be both destructive to culture as well as foster innovation. The interactions among different cultural forms of art can also be a source of cultural creativity. This intergenerativity creates biological and cultural diversity. The health of the planet as well as individual human beings depends on relationships and connections among different structures. Trees ask us to look at the importance of the processes of interrelationships not just static structures. Thus Sylvanus the god of boundaries, as manifest in a Tree Doctor character, represents transdisciplinarity.

Trees are important actors in what is called Big History [2]. Proponents of this perspective suggest that contemporary human beings can be guided by a deep understanding of the evolution of the universe and life in it. Starting with the Big Bang over 13.8 billion years ago, big historians chart first the evolution of matter and energy and then the evolution of life itself. Human beings appear remarkably late in this long journey of the universe but at this moment in history are having remarkable effects not only on each other and other species but also on entire ecosystems and in fact the geology of the planet itself. In recognition of this impact, the International
Union of Geological Sciences is considering whether we are entering another geological epoch that some have suggested calling the Anthropocene to mark the impact of our species on planetary strata.

Although not officially labeled as the Anthropocene, arguments about when such human impact started are raging and include some who believe that our major impact started when we developed agriculture. Others believe that is was the Industrial Revolution or the emergence of nuclear energy. Yet others have proposed an alternative term, the Capitalocene recognizing that the impact on the planet is not equally distributed among individuals or national groups. Market fundamentalism and a focus on individual rather than collective responsibility marks the economic and political forces labeled neoliberalism [2]. Growing economic and social disparities in essentially all countries are largely the result of many wealthy people exploiting the planet for their own personal gain and leaving a legacy of ecological devastation for future generations to address. Our overemphasis on financial measurements of success has led to the suppression of concern about other values that might actually be more life preserving. We need to reinvent concepts such as health and wealth. Health is more than the absence of the disease and should be based on more than purely 
medical models. Rather health should be viewed as ecopsychosocial in which environmental and social determinants of health should receive more attention than the current overemphasis on molecular reductionism and genetics. Individuals and communities can perceive themselves as wealthy based not purely on monetary measures but rather on quality of life. A commitment to values such as responsibilities for others now and in the future should be viewed as essential to broader ideas of health and wealth.

Trees and forests fit into this big history picture because their phylogenetic histories go back millions of years long before mammals and primates. Moreover it is their death and decay thousands of years ago that led to the deposition of fossil fuels, such as oil and coal, that we exploit today. This legacy of dead trees could be a blessing to provide energy when we really needed it. But rather than take advantage of solar and water power, we are essentially spending our children's legacy by burning fossil fuels in excess. Moreover, trees play important roles in water cycles, and it is water that is increasingly becoming a rate-limiting step in human flourishing [7]. We are running out of clean water to drink and for other needs. These are the deep time cycles of natural and geological time that are built into the biological and cultural DNA of trees. This is why to take the long-term view of human and planetary health we need to listen to and learn from trees.

\section{Conclusion}

This paper literally and figuratively represents a transdisciplinary collaboration with trees, as sources of biological and cultural wisdom. If human civilization is to survive (and it cannot in its current forms with the increasing ecological devastation), we need new understanding of systems biology, information processing, and cultural metaphors. We need new hopeful stories that promote conceptions of health and wealth that are more than just absence of disease and presence of money. Learning has been key to the success of our species so far and offers promise for making the cultural transformation we need. Intergenerative and intergenerational learning allows us to explore conceptions of time and space that will not only include human history but conceptions of the cosmos more generally. Transdisciplinarity represents a growing area of human intellectual and ethical endeavor that will contribute to the develop- ment of thoughts, ideas, values, and processes that will help promote human survival and (hopefully) flourishing.

\section{Acknowledgments}

I wish to thank the conference organizers of the 2018 ATLAS Transdisciplinary-TransnationalTranscultural (T3) International Conference, especially Basarab Nicolescu, Raymond Yeh and the Babes-Boyai University staff, faculty and leadership, for their excellent planning and transdisciplinary inspiration. Thanks also to the citizens of ClujNapoca who guided me around botanical gardens, rural farms, and haunted forests and helped me understand the history of Transylvania, the place beyond forests. Special thanks are offered to my fellow living creatures, trees.

Funding: This research received no external funding.

Conflicts of Interest: The author declare no conflict of interest.

\section{References}

[1] Nicolescu, B. (2008). Transdisciplinarity: theory and practice. Cresskill, NJ: Hampton Press.

[2] Whitehouse, P. (2017) Aging in the Anthrocene in D. DellaSala, \& M. Goldstein (Eds.) Encyclopedia of Anthropocene. Amsterdam: Elsevier.

[3] Whitehouse, P. (2003). The Rebirth of Bioethics: Extending the Original Formulations of Van Rensselaer Potter. The American Journal of Bioethics 3(4): W26-W31.

[4] Potter, V.R. \& Whitehouse, P. (1998). Deep and Global Bioethics for a Livable Third Millennium. The Scientist 12(1): 9.

[5] Whitehouse $\mathrm{P}$ The music of trees: the intergenerative tie between primary care and public health. London Journal of Primary Care, 8:2, 26-29 201.

[6] Crowther TW, Glick, H B. Covey KR, Bettigole C, Maynard DS, Thomas SM, et al. Mapping tree density at a global scale Nature 2015; 525: 201205.

[7] Wohleben, P. (2016) The Hidden Life of Trees: what they feel, how they communicatediscoveries from a secret world. Vancouver: Greystone Books.

[8] Lima, M. (2014). The Book of trees: Visualizing branches of knowledge. Princeton: Princeton Architectural Press. 
[9] Harrison, R. (1992). Forests: the shadow of civilization. Chicago: Univ of Chicago Press

[10] Kohn, E. (2013). How Forests Think: toward an anthropology beyond the human. Oakland: University of California.

[11] Whitehouse PJ, Bendezu E, FallCreek S, Whitehouse C. Intergenerational Community Schools: A New Practice for a New Time. Educ Gerontol, 2000, 26:761-770. https://www.intergenerationalschools.org/

\section{About the Author}

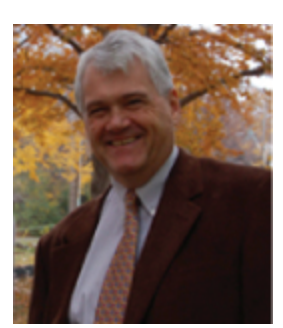

Peter J. Whitehouse, MD, Ph.D., is Professor of Neurology and former or current professor of Psychiatry, Psychology, Cognitive Science, Neuroscience, Bioethics, History, Nursing and Organizational Behavior at Case Western Reserve University, Professor of Medicine at the University of Toronto, and President of Intergenerational Schools International. He is also currently a strategic advisor in innovation at Baycrest Health Center. He received his undergraduate degree from Brown University and MD-PhD (Psychology) from The Johns Hopkins University (with field work at Harvard and Boston Universities), followed by a Fellowship in Neuroscience and Psychiatry and a faculty appointment at Hopkins. In 1986 he moved to Case Western Reserve University to develop the University Alzheimer Center. In 1999 he founded with his wife, Catherine, The Intergenerational School, a unique public multiage, community school (www.tisonline.org). He is active as a geriatric neurologist, cognitive scientist, environmental ethicist, and photographer. He is active in visual arts, dance and music organizations globally. He is a true transdisciplinarian. He is coauthor of "The Myth of Alzheimer's: what you aren't being told about today's most dreaded diagnosis." (www.themythofalzheimers.com) and hundreds of academic papers and book chapters. He also occasionally performs as Tree Doctor, a metaphorical creature who educates humans about being healthy from the perspective of a tree. 